\title{
Real Estate Soars and Financial Crises: Recent Stories
}

\author{
Hanwool Jang ${ }^{1}$, Yena Song ${ }^{2}$, Sungbin Sohn ${ }^{3, *}$ and Kwangwon Ahn ${ }^{1, *}$ (]) \\ 1 Graduate School of Future Strategy, Korea Advanced Institute of Science and Technology (KAIST), \\ Daejeon 34141, Korea; hwjangg@kaist.ac.kr \\ 2 Department of Geography, Chonnam National University, Gwangju 61186, Korea; y.song@jnu.ac.kr \\ 3 HSBC Business School, Peking University, Shenzhen 518055, China \\ * Correspondence: sungbin.sohn@phbs.pku.edu.cn (S.S.); k.ahn@kaist.ac.kr (K.A.) \\ Tel.: +86-755-2603-5324 (S.S.); +82-42-350-4032 (K.A.)
}

Received: 15 November 2018; Accepted: 28 November 2018; Published: 3 December 2018

\begin{abstract}
This paper studies the contribution of real estate bubble to a financial crisis. First, we document symptoms of a real estate bubble along with a slowdown of the real economy and find indicators of an imminent crash of the stock market, triggering a sense of déjà vu from the 2008 crisis. However, we show that the relationship between real estate and financial markets has changed since the crisis. The empirical analyses provide evidence that the monetary policy has recovered its control over mortgage rates, which had been lost prior to the global financial crisis, and that the real estate market does not have a Granger causality relationship with the stock market any more. Findings suggest that an imminent financial market crash is not likely to be catalyzed by a real estate bubble.
\end{abstract}

Keywords: financial crash; real estate bubble; stock market

\section{Introduction}

The global financial crisis in 2008 severely hit the US economy, as well as other countries. Although the US economy appears to have overcome the crisis, with some recent positive indicators (e.g., the unemployment rate dropping to 3.8\% in May 2018, the lowest in 18 years), there are other indicators that still seem potentially problematic. Indeed, business investment has not increased as much as the US government expected [1], which has important implications for sustainable economic growth. The public debt-to-GDP ratio reached $77.3 \%$ in the 1st quarter of 2018, the highest level ever for such a ratio [2]. Moreover, as of March 2018, house prices have made their biggest jump in the last four years, and half of the 50 largest metropolitan housing markets are now considered to be overvalued [3]. The heated housing markets have not become a significant problem yet, mainly due to the persistently low interest rates [4], but the Federal Reserve (Fed)'s projected serial rate increases in 2018 could jeopardize the US housing market [5]. These circumstances somehow resemble the preconditions of the global financial crisis, before which a real estate bubble seemingly fostered a financial bubble, eventually leading to a global crisis.

Various studies have tried to deepen the understanding of the relationship between real estate bubbles and financial crises. Herring and Wachter [6] analyzed the Asian financial crisis and documented the link between banking busts and real estate booms. They noted the interaction between these two markets and found that the banking sector could amplify a real estate bubble and, at the same time, the collapse of real estate prices could weaken the banking system. Sornette and Woodard [7] presented evidence that the fundamental causes of the global financial crisis had been accumulated from at least five different bubbles, namely the dot-com, real estate, mortgage-backed securities, stock, and commodities bubbles. They concluded that the interplay and mutual reinforcement of the bubbles led to the financial market crash in 2008. Similarly, Phillips and Yu [8] analyzed the timeline of the global financial crisis to examine the links between real estate, commodity, and bond markets. 
Their results showed that bubbles had emerged in the real estate market before the subprime crisis and then migrated to commodity and, finally, bond markets. The literature generally supports the notion that real estate bubbles played an important role in previous financial crises $[9,10]$.

Taking into consideration past experience and the current economic situation, a question naturally arises of whether or not the recent heating up of the housing market signals a rising probability of another financial crisis. We try to explain the risk of a potential financial crisis using the widely documented link between the financial and real estate markets. Specifically, we aim to answer the following three questions: (i) Are the current real economy and real estate market at risk? (ii) Is a financial market crash imminent? And (iii) could activity on the real estate market trigger another financial crisis?

To answer these, we first overview the prospects for the real economy and the real estate market by respectively using the yield spread and the gap between the home price index and the consumer price index. Then, we use the log-periodic power law (LPPL) model to predict when the US stock market could potentially crash. To check whether the real estate market is under control of the Federal Reserve, the time-varying interdependence between the Fed funds rate and the mortgage rate is examined. Finally, we measure whether the past values of the home price index have the ability to predict the future values of the stock market index over the last couple of decades.

We find symptoms of a real estate bubble and a slowdown of the real economy. We also find that since 2015, the monetary policy has recovered its control over mortgage rates, which it lost prior to the global financial crisis, and that after the crisis, the real estate market does not have a Granger causality relationship with the stock market any more. Although it is predicted that the US stock market is likely to crash in mid-2019 or in 2020, a real estate bubble would not be the cause of such a potential financial market crash and the development mechanism of a future crisis would be different from that of the global financial crisis in 2008.

The remainder of this paper is organized as follows. Section 2 explains the data and methodology, Section 3 presents the results and discussion, while Section 4 provides a conclusion.

\section{Data and Methodology}

\subsection{Data}

To evaluate the current situations of both the real economy and the real estate market, we investigated the yield spread and the consumer price index (CPI), as well as real estate-related indicators. The yield spread is calculated as the difference between 2-year and 10-year US Treasury notes on a daily basis. The real estate-related indicators include delinquencies on all loans (which are secured by real estate and single-family residential mortgages, and booked in domestic offices and all commercial banks. Delinquent loans and leases are the ones with their due past thirty days or more and still accruing interest, as well as those in nonaccrual status), mortgage debt outstanding (which is the amount of money which is still owed to the lender), Fed funds rates, and mortgage rates, and these are used to analyze the possibility of the formation of a real estate bubble. Loans and debt datasets are gathered quarterly, while mortgage rates and Fed funds rates are observed monthly. Furthermore, to explore the relationship between house prices and the financial market, we used the S\&P/Case-Shiller US National Home Price Index (CSI) (which measures US single-family home price and tracks monthly changes of the house price values at national level as well as in 20 metropolitan regions) and the S\&P500 index. The S\&P500 is used as a representative of the financial market. The data were obtained from Thomson Reuters Eikon and FRED.

The time span of chosen data runs from January 2000 to January 2018 to properly compare the periods before and after the global financial crisis. Descriptive statistics are presented in Table 1. The maximum value of the yield spread was observed immediately after the September 11 attacks in 2001. The maximum value of the S\&P500 was recorded prior to the global financial crisis. It was after the global financial crisis that the S\&P500 and mortgage debt outstanding recorded their minimum 
and maximum, respectively. Because debts grew at an increasing rate during the global financial crisis, the skewness of delinquencies and mortgage debt outstanding became positive. The skewness of S\&P500 is negative, which is commonly observed in the stock market [11]. S\&P500 and CSI exhibit excess kurtosis, implying drastic fluctuations of markets [11,12].

Table 1. Descriptive statistics.

\begin{tabular}{cccccccc}
\hline & Frequency & Mean & Std & Max & Min & Skewness & Kurtosis \\
\hline S\&P500 (\%) & Daily & 0.0146 & 1.2120 & 10.9572 & -9.4695 & -0.2083 & 11.6945 \\
Yield spread (\%) & Daily & 1.4237 & 0.8897 & 2.9100 & -0.5200 & -0.4182 & 2.1092 \\
CSI (\%) & Monthly & 0.3125 & 0.8094 & 2.0170 & -2.2844 & -0.6118 & 3.2687 \\
CPI (\%) & Monthly & 0.1791 & 0.3035 & 1.3675 & -1.7864 & -1.3296 & 12.1315 \\
Fed funds rate (\%) & Monthly & 1.7591 & 2.0121 & 6.5400 & 0.0700 & 1.0421 & 2.6726 \\
Mortgage rate (\%) & Monthly & 5.2923 & 1.2998 & 8.5150 & 3.3450 & 0.3286 & 2.1742 \\
Delinquencies (m\$) & Quarterly & 98,555 & 76,937 & 237,837 & 16,632 & 0.4733 & 1.6969 \\
Mortgage debt (m\$) & Quarterly & 794,479 & 846,463 & $1,870,040$ & 20,363 & 0.2039 & 1.0575 \\
\hline
\end{tabular}

\subsection{Log-Periodic Power Law}

Recently, various attempts have been made to introduce bubbles into asset pricing models. Predominantly, two streams of theoretical frameworks have elucidated this issue: Rational models [13] and behavioral models [14]. Although a substantial amount of empirical evidence supports the validation of these models, none of them have been able to considerably predict the specific timing of financial bubbles. One alternative to explaining bubbles is a framework called the LPPL model, which has become popular [15-17]. It was first introduced in statistical physics, and subsequently gained wider attention from econophysics because of its successful prediction of financial crashes [18-21]. In this model, traders are organized into networks and choose one of two states: Buy or sell. Their trading actions depend on the decisions of other traders and these interactions let agents form groups with self-similar behavior $[22,23]$. During a boom period, some traders invest in assets with overconfidence and other investors in the same network imitate one another. The resultant increase in the asset value leads to speculative reinvestment and this loop repeats over time. Such positive feedback continues up to a certain point, often called the critical time, and the LPPL model can predict the crash date of bubbles $[24,25]$. The critical time can be detected by examining the signature of a faster-than-exponential growth (super-exponential, hyperbolic, or power law) and its decoration by log-periodic oscillations [26-33].

Mathematically, these ideas can be captured by an extension of the power law equation as follows:

$$
Y_{t}=A+B\left(t_{c}-t\right)^{\beta}\left\{1+C \cos \left[\omega \ln \left(t_{c}-t\right)-\phi\right]\right\} \quad \text { for } t<t_{c}
$$

where $Y_{t}>0$ is the log of the asset price at time $t, t_{c}>0$ is the critical time, $A>0$ is the log price at the critical time $t_{c}, B<0$ is the size of increase in $Y_{t}$ over the time before the crash when $C$ is close to $0, C \in[-1,1]$ controls the magnitude of the oscillations around the exponential trend, $\beta \in[0,1]$ is the exponent of the power law growth, $\omega>0$ is the frequency of the fluctuations during the bubble, and $\phi \in[0,2 \pi]$ is a phase parameter.

In this study, seven parameters in the LPPL model were estimated such that the root mean square error (RMSE) between the observed and predicted log asset prices is minimized [15]:

$$
R M S E=\sqrt{\frac{1}{T} \sum_{t=1}^{T}\left(y_{t}-Y_{t}\right)^{2}},
$$

where $y_{t}\left(Y_{t}\right)$ stands for the log of observed (predicted) asset price at time $t$ and $T$ is the number of trading days in the sample period. 
We used the S\&P500 index for the asset price. In order to estimate the parameters accurately, we simulated the initial values for the parameters with a price gyration method and optimized these parameters using a nonlinear optimization, called a genetic algorithm [21,34-39].

\subsection{Generalized Spillover Analysis}

Mortgage rate is an important factor that determines demand in the real estate market and the Fed funds rate, controlled by the Federal Reserve, is a main benchmark rate in financial markets. Given that a prolonged period of low mortgage rates is often cited as a cause of the real estate bubble and ultimately the global financial crisis [40], it is important to examine whether the relevant monetary authority is capable of managing the mortgage rate or not.

For this purpose, we investigated the time-varying interdependence between the Fed funds rates and the mortgage rates using the generalized spillover analysis. This analysis can measure the extent to which a shock in one variable can explain the forecast error variance of the other variable. In other words, the analysis signifies which variable is more affected by the other. The analysis is implemented by considering a $\operatorname{VAR}(p): \mathbb{Y}_{t}=\sum_{k=1}^{p} \Phi_{k} \mathbb{Y}_{t-k}+u_{t}$, where $\mathbb{Y}_{t}$ is an $N$-dimensional vector of zero-mean stationary state variables $\left(\mathbb{Y}_{t}^{1}, \mathbb{Y}_{t}^{2}, \cdots, \mathbb{Y}_{t}^{N}\right)$ and $u_{t}$ is a vector of independent and identically distributed disturbances with a covariance matrix $\Sigma$. Then, $\mathbb{Y}_{t}$ can be written in the form of a vector moving average: $\mathbb{Y}_{t}=\sum_{k=0}^{\infty} \Psi_{k} \epsilon_{t-k}$ for some $\left\{\Psi_{k}\right\}_{k=0}^{\infty}[41]$.

We conducted the variance decomposition, which is invariant to the order of the state variables $[42,43]$, using the Fed funds rates and the mortgage rates. The variance decomposition denotes the fraction of the $H$-step-ahead error variance in forecasting the state variable $i$ that is due to the shock in state variable $j$ :

$$
\theta_{i j}^{g}(H)=\frac{\sigma_{j j}^{-1} \sum_{h=0}^{H-1}\left(e_{i}^{\prime} \Psi_{h} \Sigma e_{j}\right)^{2}}{\sum_{h=0}^{H-1}\left(e_{i}^{\prime} \Psi_{h} \Sigma \Psi_{h}^{\prime} e_{i}\right)},
$$

where $\sigma_{j j}$ is the variance of the innovation in the $j$ th equation and $e_{i}$ is a row vector of 1 on the $i$ th entry and 0 otherwise. $\theta_{i j}^{g}(H)$ represents the $H$-step-ahead cross variance shares or the gross spillover from state variable $j$ to state variable $i$. The gross spillover is then normalized as:

$$
\tilde{\theta}_{i j}^{g}(H)=\frac{\theta_{i j}^{g}(H)}{\sum_{j=1}^{N} \theta_{i j}^{g}(H)},
$$

which implies that the gross spillover from all variables (including itself) is 1 . The net spillover from variable $j$ to variable $i$ is calculated as:

$$
\tilde{\theta}_{i j}^{n}(H)=\tilde{\theta}_{i j}^{g}(H)-\tilde{\theta}_{j i}^{g}(H),
$$

which is the difference between the gross spillover from variable $j$ to $i$ and that from variable $i$ to $j$. In this paper, we examined its absolute value, which represents the intensity of the volatility spillover; the lag length $(p)$ of VAR is chosen based on Akaike information criteria. For the calculation of the spillover intensity, we used a 12-month horizon $(H=12)$.

\subsection{Granger Causality Test}

Granger [44] suggested a method to detect a causal direction between two time series data, namely the Granger causality test. Specifically, the Granger causality test detects a correlation between the current value of one variable and the past values of another [45]. Based on Granger's definition, Sims [46] proposed a variant. Consider a bivariate VAR model with two time series $x_{1}$ and $x_{2}$ :

$$
\Delta x_{1, t}=\alpha_{1}+\sum_{i=1}^{q} \beta_{11, i} \Delta x_{1, t-i}+\sum_{j=1}^{q} \beta_{12, j} \Delta x_{2, t-j}+v_{1, t}
$$




$$
\Delta x_{2, t}=\alpha_{2}+\sum_{i=1}^{q} \beta_{21, i} \Delta x_{2, t-i}+\sum_{j=1}^{q} \beta_{22, j} \Delta x_{1, t-j}+v_{2, t},
$$

where $\Delta$ is the difference operator, $q$ is the number of lags, $\alpha$ and $\beta$ are coefficient parameters to be estimated, and $v$ is an error term.

To test whether $x_{2}$ Granger-causes $x_{1}$, the null $\left(H_{0}\right)$ hypothesis is set up as $H_{0}: \beta_{12, j}=0$ for $j=1,2, \ldots, q$. If $H_{0}$ is rejected, i.e., at least one of $\beta_{12, j}$ 's is not equal to zero, then it suggests that the past value of $x_{2}$ has significant linear predicative power on the current value of $x_{1}: x_{2}$ Granger-causes $x_{1}$. We tested the Granger causality between the time series of S\&P500 and CSI.

\section{Results and Discussion}

\subsection{Diagnosis of the Real Economy and the Real Estate Market}

Figure 1a shows that the yield spread approached approximately 0.5 percentage points in 2017. The yield spread previously fell to this level in 2005 and then became inverted before the global financial crisis. Typically, when an economy is in good health, the long-term bond yield is higher than the short-term ones [47]. By contrast, when an economy does not appear vibrant, investors are not willing to take risks of recession, lowering the yield of long-term bonds [48]. As a result, spreads between long-term and short-term bonds decrease and could turn negative in a recession. The current trend implies that the yield spread could shrink even further and turn negative, signaling an economic slowdown or even a recession [49].

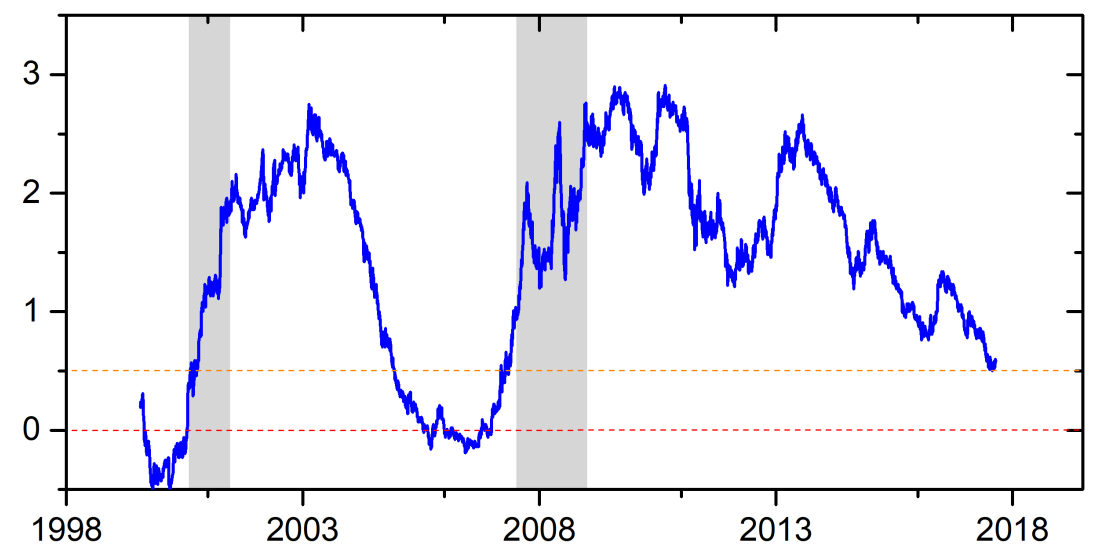

(a) Yield spread

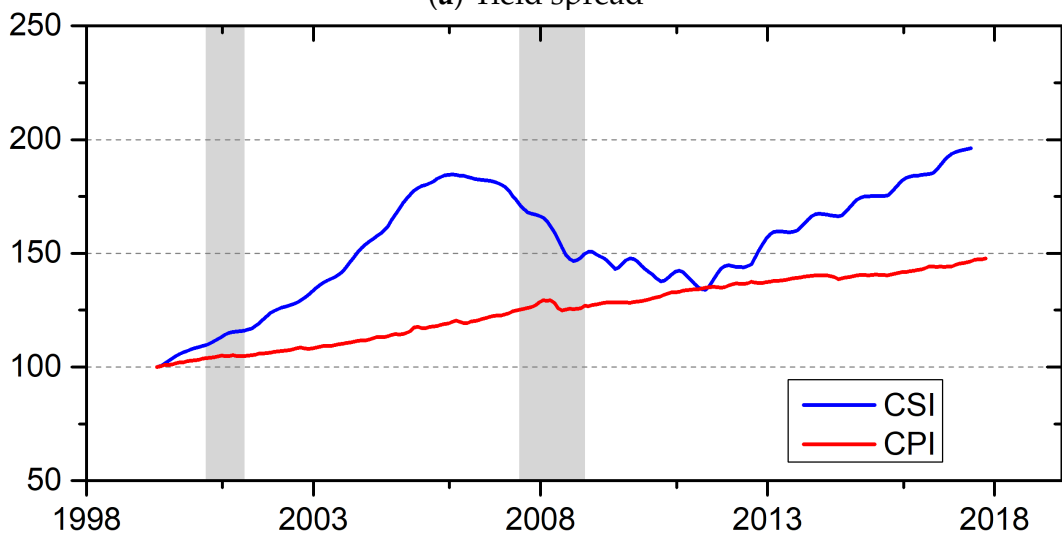

(b) Real estate residential index vs. consumer price index (CPI)

Figure 1. Signs of economic downturn and real estate bubble. Shaded areas are the recession periods defined by the National Bureau of Economic Research.

As a proxy for inflation and the residential real estate price level, the CPI and CSI were compared. Figure $1 \mathrm{~b}$ indicates that when the levels are set to 100 in 2000, CSI has been constantly greater than CPI 
since 2000 and the gap between these two indices has widened since 2012. The level of CSI rapidly increased up to 196 points in 2017, whereas CPI's increase has been steady and gradual. As a result, the gap between CSI and CPI exceeded 50 points in 2017. A similar pattern was noted in 2005, a year before the real estate market collapsed. During a bubble period, asset prices rise quickly, while inflation stays comparatively stable [50]. In light of this, these indices point out that the US real estate market is at risk of a housing bubble.

\subsection{Risk of Financial Crash}

To measure the risk in the financial market, the exponential growth $\left(t_{c}-t\right)^{\beta}$ and log-periodic oscillation $\cos \left[\omega \ln \left(t_{c}-t\right)\right]$ were estimated from Equation (1) using the S\&P500 index. As the critical time approaches, both the gradient of exponential growth and the frequency of log-periodic oscillation tend to increase. Therefore, the simultaneous increase of these two indicates an imminent market crash [51]. Figure 2a implies that the gradient of exponential growth and the frequency of log-periodic oscillation are increasing. Furthermore, using the German stock index, Kurz-Kim [51] provided empirical evidence of the imminence of critical time, in which the gradient of exponential growth increases from $0.27 \%$, to $0.67 \%$, to $1.70 \%$, to $4.29 \%$, to $12.9 \%$, while the period of log-periodic oscillation decreases by $60 \%$ in each interval from 255 , to 102 , to 41 , to 16 , to 7 trading days. Our analysis notes that the exponential growth rate is greater than $0.27 \%$, i.e., $0.1 \%$ and $0.59 \%$ at the second and third peaks, respectively, and is about to enter the second stage of the example in Reference [51]. Meanwhile, the period of log oscillation in our analysis decreased by $75 \%$ from 1933 to 496 trading days. Our result implies that the critical time of a financial bubble is getting closer.

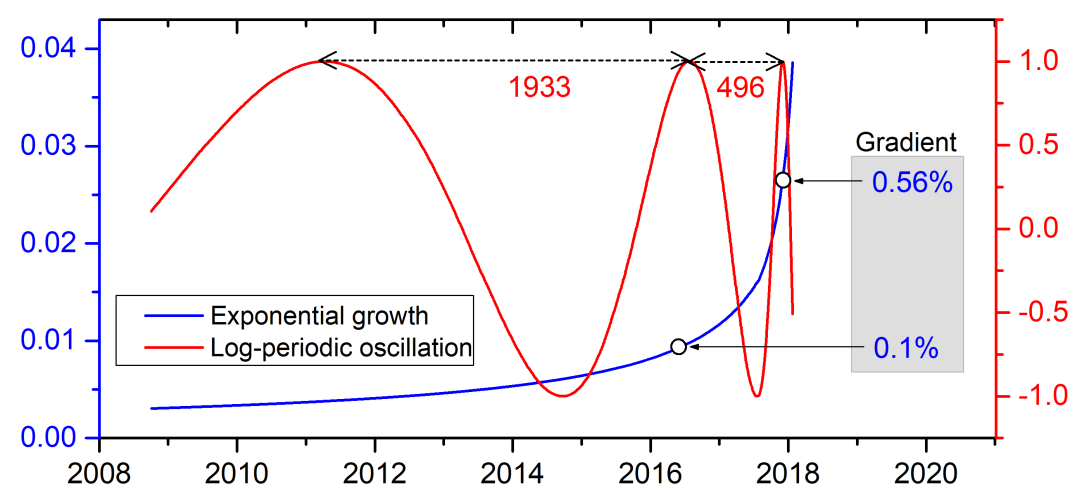

(a) Exponential growth (left) and log-periodic oscillation (right)

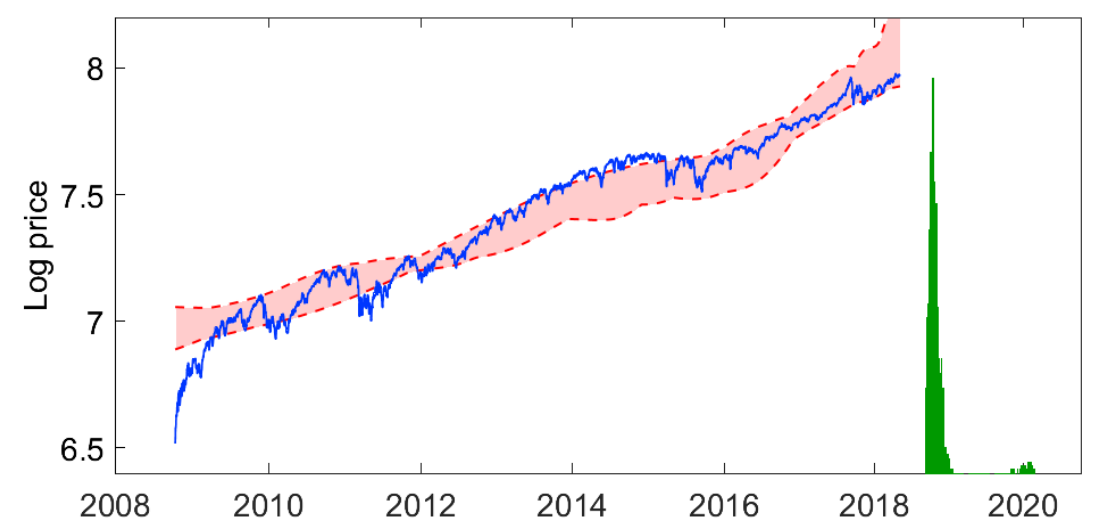

(b) Logarithm of the stock price and corresponding alarms

Figure 2. Early warning indicators.

The date of a potential crash can be predicted using the LPPL model. We simulated 1000 cycles of the LPPL model with the same time span from March 2009 to July 2018. Based on Johansen and 
Sornette [52] and Brée and Joseph [53], we selected the data period for LPPL as follows: (i) The time window starts at the end of the previous crash, which is defined as the lowest point since the last crash, and (ii) the endpoint is the last day of the dataset to predict the future critical time of a bubble. From each simulated sample, we estimated the critical time and obtained the time series of the predicted log stock price. The $95 \%$ prediction interval of the log stock price (red shaded area) and its corresponding critical time (green bars) are depicted in Figure $2 \mathrm{~b}$. The occurrence of crashes is a random phenomenon which happens with an increasing probability as the critical time approaches [18]. Our results suggest that a crash is likely to happen in mid-2019 and 2020, with a probability of $97 \%$ and 3\%, respectively, implying an imminent burst of bubbles. The parameter estimates are reported in Table 2. The parameter estimates satisfy the two conditions $B<0$ and $0.1 \leq \beta \leq 0.9$, ensuring a faster than exponential acceleration of the log price with a vertical slope at the critical time $t_{c}$ [54]. The value of $\omega(=5.90)$ corroborates existing studies such as that by Johansen [55], who found that $\omega \approx 6.36 \pm 1.56$ for 30 crashes in major financial markets. As the critical time approaches, a large amount of simultaneous sell-offs can be a dominant behavior creating order, and at the same time, idiosyncratic signals may cause disorder to fight imitating behaviors [21]. At a certain critical point, order wins disorder and a crash happens. Based on the analysis results, it can be argued that the current US financial market is at a risky stage.

Table 2. LPPL parameters of best fit.

\begin{tabular}{ccccccc}
\hline $\boldsymbol{A}$ & $\boldsymbol{B}$ & $\boldsymbol{t}_{\boldsymbol{c}}$ & $\boldsymbol{\beta}$ & $\boldsymbol{C}$ & $\boldsymbol{\omega}$ & $\boldsymbol{\phi}$ \\
\hline 8.22 & -0.001 & 2832.52 & 0.85 & -0.07 & 5.90 & 0.95 \\
\hline
\end{tabular}

\subsection{Impact of the Real Estate Market on a Financial Crash}

We investigated Fed funds rates and mortgage rates, which were the primary contributors to the real estate bubble prior to the global financial crisis [40]. After the 2001 recession, the Fed kept the Fed funds rates low from 2002 to 2004 to revitalize the economy. Low-income households were able and willing to pay monthly mortgage payments not only due to low mortgage rates, but also due to the appreciation of house prices. This led to a housing boom and an unsustainable mortgage market.

Before conducting formal analyses, we first visually checked the outstanding mortgage debt and delinquencies on all loans. Figure 3a shows that delinquencies started rising from 2006. After that, the mortgage debt dramatically increased around 2008, which was mainly due to a substantial amount of subprime loans offered to high-risk applicants [56]. In 2017, unlike in 2008, delinquencies on all loans consistently decreased, while the outstanding mortgage debt mildly increased. In short, the recent real estate market does not appear to be as exuberant as in 2008.

We then analyzed the intensity of the volatility spillover between Fed funds rates and mortgage rates. Figure 3b shows a strong volatility spillover between 2001 and 2006, except for 2004. Jarocinski and Smets [57] claimed that the recent US monetary policy takes house prices into account, indicating that the stance of monetary policy changes over time. However, starting from August 2007, mortgage rates and Fed funds rates became insulated from each other, with low volatility spillover intensity. This trend continued until the European sovereign debt crisis in 2011. This implies that monetary policy might have lost its control over mortgage rates because the nominal interest rate remained essentially at zero [58]. Meanwhile, the intensity of the volatility spillover between Fed funds rates and mortgage rates has been restored since 2015. This indicates that the monetary policy appears to be recovering its control over mortgage rates and thus the real estate market has become manageable to some extent. This points out that the current circumstances of the real estate market are different from those that preceded the global financial crisis. 


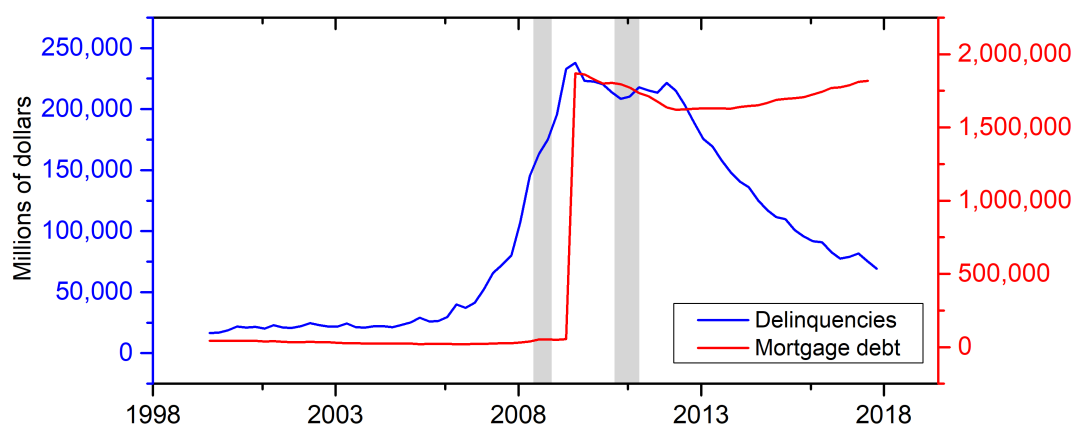

(a) Delinquencies (left) and outstanding mortgage debt (right)

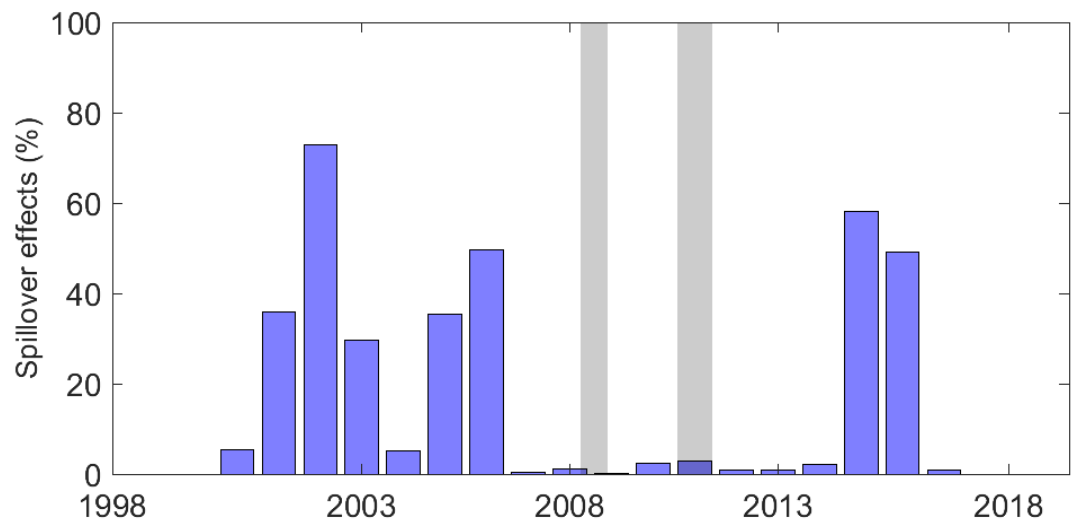

(b) Spillover intensity between Fed funds rates and mortgage rates

Figure 3. Indicators of the real estate market. Volatility spillover intensity is obtained as described in Section 2.3. Shaded areas are the global financial crisis, September 2008-May 2009 [59], and European sovereign debt crisis, January 2011-November 2011 [60].

Figure 3 indicates that the economy could have operated under different regimes before and after the global financial crisis. To test this possibility, we investigated the relationship between the real estate market and the financial market using subsamples. We restructured data into the four following sets: Whole period (2000-2018), pre-crisis (2003-2008), in-crisis (2008-2009), and post-crisis (2009-2018). The starting point of the pre-crisis period is the end of the dot-com bubble and the last point is the before the global financial crisis. The in-crisis period covers the global financial crisis, September 2008-May 2009 [59]. The post-crisis period covers the period after the global financial crisis until the latest dataset.

We conducted the Granger causality test to assess the null hypothesis that S\&P500 (CSI) does not Granger-cause CSI (S\&P500) in Table 3. During the whole period, S\&P500 Granger-causes CSI, implying that there exists positive feedback from the stock market to the real estate market [61]. However, in the pre-crisis period, it is CSI that Granger-causes S\&P500, not the other way around. The results are robust to various test windows before the global financial crisis. This finding provides empirical evidence that prior to the global financial crisis, the real estate market indeed contained predictive information about the stock market. This is consistent with the view that the real estate market was largely responsible for the global financial crisis [8-10]. In the in-crisis period, there is no Granger causality relationship. This is probably due to the turbulence and high uncertainty experienced in the stock and real estate markets during the global financial crisis. After the crash, however, the direction changed. The stock market Granger-causes the real estate market, but the real estate market does not Granger-cause the stock market. The result does not change even after shifting the starting point of the time window forward from the global financial crisis. Interestingly, the test results between the pre- and post-crisis periods are contrasting. This also confirms the different circumstances in the current real estate market. 
Table 3. Granger causality tests between S\&P500 and CSI.

\begin{tabular}{|c|c|c|c|}
\hline & Period & Causal Direction & Chi-Square \\
\hline \multirow{2}{*}{ Whole-period } & \multirow{2}{*}{ 2000.01-2018.01 } & S\&P500 $\rightarrow$ CSI & $9.42^{* *}$ \\
\hline & & $\mathrm{CSI} \rightarrow \mathrm{S} \& \mathrm{P} 500$ & 2.33 \\
\hline \multirow{8}{*}{ Pre-crisis } & \multirow{2}{*}{ 2003.03-2008.08 } & S\&P500 $\rightarrow$ CSI & 3.04 \\
\hline & & $\mathrm{CSI} \rightarrow \mathrm{S} \& \mathrm{P} 500$ & $14.05^{* * *}$ \\
\hline & \multirow{2}{*}{ 2003.03-2008.07 } & S\&P500 $\rightarrow$ CSI & 3.18 \\
\hline & & CSI $\rightarrow$ S\&P500 & $13.68^{* * *}$ \\
\hline & \multirow{2}{*}{ 2003.03-2008.06 } & S\&P500 $\rightarrow$ CSI & 0.48 \\
\hline & & CSI $\rightarrow$ S\&P500 & $13.34^{* * *}$ \\
\hline & \multirow{2}{*}{ 2003.03-2008.05 } & S\&P500 $\rightarrow$ CSI & 0.33 \\
\hline & & $\mathrm{CSI} \rightarrow \mathrm{S} \& \mathrm{P} 500$ & $13.80^{* * *}$ \\
\hline \multirow{2}{*}{ In-crisis } & \multirow{2}{*}{ 2008.09-2009.05 } & S\&P500 $\rightarrow$ CSI & 0.71 \\
\hline & & $\mathrm{CSI} \rightarrow \mathrm{S} \& \mathrm{P} 500$ & 1.03 \\
\hline \multirow{8}{*}{ Post-crisis } & \multirow{2}{*}{ 2009.06-2018.01 } & S\&P500 $\rightarrow$ CSI & $14.23^{* * *}$ \\
\hline & & $\mathrm{CSI} \rightarrow \mathrm{S} \& \mathrm{P} 500$ & 1.88 \\
\hline & \multirow{2}{*}{ 2009.07-2018.01 } & S\&P500 $\rightarrow$ CSI & $14.12^{* * *}$ \\
\hline & & $\mathrm{CSI} \rightarrow \mathrm{S} \& \mathrm{P} 500$ & 1.48 \\
\hline & \multirow{2}{*}{ 2009.08-2018.01 } & S\&P500 $\rightarrow$ CSI & $14.92^{* * *}$ \\
\hline & & $\mathrm{CSI} \rightarrow \mathrm{S} \& \mathrm{P} 500$ & 1.31 \\
\hline & \multirow{2}{*}{ 2009.09-2018.01 } & S\&P500 $\rightarrow$ CSI & $14.78^{* * *}$ \\
\hline & & $\mathrm{CSI} \rightarrow \mathrm{S} \& \mathrm{P} 500$ & 1.31 \\
\hline
\end{tabular}

Note: $* *$ and $* * *$ indicate significance level at the $5 \%$ and $1 \%$, respectively. We used the 1 st difference of log data except for pre-crisis and in-crisis, where we applied the 2nd difference of log data. Lag length was selected on the basis of the Schwarz Bayesian information criterion (SBIC), Hannan-Quinn information criterion (HQIC), and likelihood-ratio (LR) tests.

\section{Conclusions}

Three research questions were raised at the beginning of this study and we have tried to answer all of them by analyzing various economic indices in the US. From an extensive analysis, we could draw a conclusion for each question, and these are outlined as follows. First, recent economic indicators, such as the yield spread, CPI, and CSI, do indeed point to a recession and a real estate bubble in the US. Second, the LPPL model further indicates an imminent financial market crash, possibly within six months to a year. Third, the real estate market would not be likely to induce another market crash as it did the last time, but the opposite could happen.

As such, our results imply that if everything remains as it is, we will soon witness another financial crisis, which would not have developed through the same path as the last global financial crisis due to lessons having been learned previously. This indirectly suggests that other parts of the economy should be more carefully and thoroughly monitored and maintained than the real estate sector to push forward the critical time. A short window of time to the market crash asks for immediate actions to develop a more sustainable and resilient economic environment.

Author Contributions: Conceptualization, K.A., S.S. and Y.S.; methodology, K.A. and S.S.; software, H.J.; validation, K.A., S.S. and Y.S.; formal analysis, K.A., S.S., Y.S. and H.J.; investigation, K.A., S.S., Y.S. and H.J.; resources, K.A. and S.S.; data curation, H.J.; writing—original draft preparation, H.J.; writing—review and editing, K.A., S.S. and Y.S.; visualization, H.J.; supervision, K.A. and S.S.; project administration, H.J.; funding acquisition, K.A. and S.S.

Funding: This work was supported by KAIST through the Moon Soul Graduate School of Future Strategy (K.A.) and by Peking University HSBC Business School through Bairui Trust Research Funds (S.S. and K.A.).

Conflicts of Interest: The authors declare no conflict of interest. 


\section{References}

1. Farrell, C. Is the next recession on its way? Forbes, 3 August 2018.

2. Bernstein, J. The question isn't when is the next recession coming; It's what are we going to do about it. Washington Post, 5 July 2018.

3. Olick, D. Housing confidence hits record high as home prices skyrocket. Consumer News and Business Channel, 7 May 2018 .

4. Colvin, G. The end is near for the economic boom. Fortune, 19 July 2018.

5. Gopal, P. This rare bear who called the crash warns housing is too hot again. Bloomberg, 23 January 2018.

6. Herring, R.; Wachter, S. Bubbles in real estate markets. In Asset Price Bubbles: The Implications for Monetary, Regulatory, and International Policies; Hunter, W., Kaufman, G., Pomerleano, M., Eds.; MIT Press: Cambridge, MA, USA, 2003; pp. 217-230.

7. Sornette, D.; Woodard, R. Financial bubbles, real estate bubbles, derivative bubbles, and the financial and economic crisis. In Econophysics Approaches to Large-Scale Business Data and Financial Crisis; Takayasu, M., Watanabe, T., Takayasu, H., Eds.; Springer: Berlin/Heidelberg, Germany, 2010; pp. 101-148.

8. Phillips, P.C.; Yu, J. Dating the timeline of financial bubbles during the subprime crisis. Quant. Econ. 2011, 2, 455-491. [CrossRef]

9. Mishkin, F.S. Over the cliff: From the subprime to the global financial crisis. J. Econ. Perspect. 2011, 25, 49-70. [CrossRef]

10. Shiller, R.J. The Subprime Solution: How Today's Global Financial Crisis Happened, and What to Do About It; Princeton University Press: Princeton, NJ, USA, 2012; pp. 29-70.

11. Campbell, J.Y.; Hentschel, L. No news is good news: An asymmetric model of changing volatility in stock returns. J. Financ. Econ. 1992, 31, 281-318. [CrossRef]

12. Frankland, R.; Smith, A.; Wilkins, T.; Varnell, E.; Holtham, A.; Biffis, E.; Eshun, S.; Dullaway, D. Modelling extreme market events. A report of the benchmarking stochastic models working party. Br. Actuar. J. 2009, 15, 99-201. [CrossRef]

13. Allen, F.; Morris, S.; Postlewaite, A. Finite bubbles with short sale constraints and asymmetric information. J. Econ. Theory 1993, 61, 206-229. [CrossRef]

14. Brunnermeier, M.K. Bubbles. In Banking Crises; Springer: Berlin/Heidelberg, Germany, 2016; pp. 28-36.

15. Johansen, A.; Ledoit, O.; Sornette, D. Crashes as critical points. Int. J. Theor. Appl. Financ. 2000, 3, $219-255$. [CrossRef]

16. Clark, A. Evidence of log-periodicity in corporate bond spreads. Phys. A 2004, 338, 585-595. [CrossRef]

17. Filimonov, V.; Sornette, D. A stable and robust calibration scheme of the log-periodic power law model. Phys. A 2013, 392, 3698-3707. [CrossRef]

18. Johansen, A.; Sornette, D. Critical crashes. Risk 1999, 12, 91-94.

19. Johansen, A.; Sornette, D.; Ledoit, O. Predicting financial crashes using discrete scale invariance. J. Risk 1999, 1, 5-32. [CrossRef]

20. Zhou, W.; Sornette, D. A case study of speculative financial bubbles in the South African stock market 2003-2006. Phys. A 2009, 388, 869-880. [CrossRef]

21. Dai, B.; Zhang, F.; Targia, D.; Ahn, K. Forecasting financial crashes: Revisit to log-periodic power law. Complexity 2018, 4237471. [CrossRef]

22. Geraskin, P.; Fantazzini, D. Everything you always wanted to know about log-periodic power laws for bubble modeling but were afraid to ask. Eur. J. Financ. 2013, 19, 366-391. [CrossRef]

23. Sornette, D. Why Stock Markets Crash: Critical Events in Complex Financial Systems; Princeton University Press: Princeton, NJ, USA, 2017; Chapter 3, pp. 82-133.

24. Zhou, W.; Sornette, D. Is there a real-estate bubble in the US? Phys. A 2006, 361, 297-308. [CrossRef]

25. Jang, H.; Ahn, K.; Kim, D.; Song, Y. Detection and prediction of house price bubbles: Evidence from a new city. In Lecture Notes in Computer Science; Springer: Cham, Switzerland, 2018; Volume 10862, pp. 782-795.

26. Zhou, W.; Sornette, D. 2000-2003 real estate bubble in the UK but not in the USA. Phys. A 2003, 329, $249-263$. [CrossRef]

27. Vandewalle, N.; Boveroux, P.; Minguet, A.; Ausloos, M. The crash of October 1987 seen as a phase transition: Amplitude and universality. Phys. A 1998, 255, 201-210. [CrossRef] 
28. Vandewalle, N.; Ausloos, M.; Boveroux, P.; Minguet, A. Visualizing the log-periodic pattern before crashes. Eur. Phys. J. B Condens. Matter Complex Syst. 1999, 9, 355-359. [CrossRef]

29. Drozdz, S.; Ruf, F.; Speth, J.; Wójcik, M. Imprints of log-periodic self-similarity in the stock market. Eur. Phys. J. B Condens. Matter Complex Syst. 1999, 10, 589-593. [CrossRef]

30. Feigenbaum, J.A. A statistical analysis of log-periodic precursors to financial crashes. Quant. Financ. 2001, 1, 346-360. [CrossRef]

31. Feigenbaum, J.A.; Freund, P.G. Discrete Scale Invariance and the "Second Black Monday". Mod. Phys. Lett. B 1998, 12, 57-60. [CrossRef]

32. Drozdz, S.; Kwapien, J.; Oswiecimka, P. Criticality characteristics of current oil price dynamics. Acta Phys. Pol. A 2008, 114, 699-702. [CrossRef]

33. Czarnecki, Ł.; Grech, D.; Pamuła, G. Comparison study of global and local approaches describing critical phenomena on the Polish stock exchange market. Phys. A 2008, 387, 6801-6811. [CrossRef]

34. Korzeniowski, P.; Kuropka, I. Forecasting the critical points of stock markets' indices using log-periodic power law. Ekonometria 2013, 1, 100-110.

35. Jacobsson, E. How to Predict Crashes in Financial Markets with the Log-Periodic Power Law. Master Dissertation, Department of Mathematical Statistics, Stockholm University, Stockholm, Sweden, 2009.

36. Liberatore, V. Computational LPPL fit to financial bubbles. arXiv 2010, arXiv:1003.2920.

37. Cvijović, D.; Klinowski, J. Taboo search: An approach to the multiple minima problem. Science 1995, 267, 664-666. [CrossRef] [PubMed]

38. Fantazzini, D. Modeling bubbles and anti-bubbles in bear markets. In The Handbook of Trading; McGRAW-HILL: New York, NY, USA, 2010; pp. 365-388.

39. Filimonov, V.; Demos, G.; Sornette, D. Modified profile likelihood inference and interval forecast of the burst of financial bubbles. Quant. Financ. 2017, 17, 1167-1186. [CrossRef]

40. Holt, J. A summary of the primary causes of the housing bubble and the resulting credit crisis: A non-technical paper. J. Bus. Inq. 2009, 8, 120-129.

41. Wold, H. Causality and econometrics. Econometrica 1954, 22, 162-177. [CrossRef]

42. Pesaran, H.H.; Shin, Y. Generalized impulse response analysis in linear multivariate models. Econ. Lett. 1998, 58, 17-29. [CrossRef]

43. Diebold, F.X.; Yilmaz, K. Better to give than to receive: Predictive directional measurement of volatility spillovers. Int. J. Forecast. 2012, 28, 57-66. [CrossRef]

44. Granger, C.W. Investigating causal relations by econometric models and cross-spectral methods. Econometrica 1969, 37, 424-438. [CrossRef]

45. Chiou-Wei, S.Z.; Chen, C.F.; Zhu, Z. Economic growth and energy consumption revisited: Evidence from linear and nonlinear Granger causality. Energy Econ. 2008, 30, 3063-3076. [CrossRef]

46. Sims, C.A. Macroeconomics and reality. Econometrica 1980, 48, 1-48. [CrossRef]

47. Phillips, M. What's the yield curve? 'A powerful signal of recessions' has wall street's attention. New York Times, 5 June 2018.

48. Ang, A.; Piazzesi, M.; Wei, M. What does the yield curve tell us about GDP growth? J. Econom. 2006, 131, 359-403. [CrossRef]

49. Rudebusch, G.D.; Williams, J.C. Forecasting recessions: The puzzle of the enduring power of the yield curve. J. Bus. Econ. Stat. 2009, 27, 492-503. [CrossRef]

50. Shiratsuka, S. The asset price bubble in Japan in the 1980s: Lessons for financial and macroeconomic stability. Bank Int. Settl. Pap. 2005, 21, 42-62.

51. Kurz-Kim, J.R. Early warning indicator for financial crashes using the log periodic power law. Appl. Econ. Lett. 2012, 19, 1465-1469. [CrossRef]

52. Johansen, A.; Sornette, D. Bubbles and anti-bubbles in Latin-American, Asian and Western stock markets: An empirical study. Int. J. Theor. Appl. Financ. 2001, 4, 853-920. [CrossRef]

53. Brée, D.S.; Joseph, N.L. Testing for financial crashes using the log periodic power law model. Int. Rev. Financ. Anal. 2013, 30, 287-297. [CrossRef]

54. Lin, L.; Ren, R.; Sornette, D. The volatility-confined LPPL model: A consistent model of 'explosive' financial bubbles with mean-reverting residuals. Int. Rev. Financ. Anal. 2014, 33, 210-225. [CrossRef]

55. Johansen, A. Characterization of large price variations in financial markets. Phys. A 2003, 324, 157-166. [CrossRef] 
56. Christofi, A.; Christofi, P.; Malindretos, J. Lessons from the 2007-2008 financial crisis and action for the future. Int. J. Econ. Res. 2011, 8, 45-60.

57. Jarocinski, M.; Smets, F. House Prices and the Stance of Monetary Policy; European Central Bank: Frankfurt, Germany, 2008.

58. Taylor, J.B. Economic policy and the financial crisis: An empirical analysis of what went wrong. Crit. Rev. 2009, 21, 341-364. [CrossRef]

59. Hagen, J.; Schuknecht, L.; Wolswijk, G. Government bond risk premiums in the EU revisited: The impact of the financial crisis. Eur. J. Political Econ. 2011, 27, 36-43. [CrossRef]

60. Frutos, J.C.; Garcia-de Andoain, C.; Heider, F.; Papsdorf, P. Stressed Interbank Markets: Evidence From the European Financial and Sovereign Debt Crisis; European Central Bank: Frankfurt, Germany, 2016.

61. Woo, S. STATA for Economic Analysis; Jiphil Media: Seoul, Korea, 2016; Chapter 15, pp. 255-264.

(C) 2018 by the authors. Licensee MDPI, Basel, Switzerland. This article is an open access article distributed under the terms and conditions of the Creative Commons Attribution (CC BY) license (http://creativecommons.org/licenses/by/4.0/). 